\title{
Correlations between heat release rate and gaseous by-product concentrations applied to the characterization of forest fuels
}

I. Fernández-Gómez ${ }^{1}$, J. Madrigal ${ }^{2}$, A. J. de Castro ${ }^{1}$, M. Guijarro ${ }^{2}$, J. M. Aranda ${ }^{1}$, C. Diez 2 , C. Hernando ${ }^{2} \&$ F. López ${ }^{1}$

${ }^{1}$ LIR laboratory, Departamento de Física, Universidad Carlos III de Madrid, Spain

${ }^{2}$ Centro de Investigación Forestal, Instituto Nacional de Investigación y

Tecnología Agraria y Alimentaria (CIFOR-INIA), Spain

\begin{abstract}
In this work an adapted bench-scale Mass Loss Calorimeter (MLC) device is used to measure HRR for forest fuels. The MLC has the same heating unit as a standard cone calorimeter, but a) the physical basis to measure HRR in a MLC (by using a calibrated thermopile) is different than the one used in the standard cone calorimeter (oxygen consumption method) and b) the MCL does not have a unit to measure the concentration of the gases produced during the combustion. Although the concentration values are not essential to measure the HRR curves, their knowledge is of great interest to characterize the combustion process and the combustion efficiency. In this sense, a Fourier transform based spectroradiometer (FTIR) has been adapted to the MLC in a short open-path configuration to measure "in situ" the concentration of carbon monoxide and dioxide and water vapour, nearly simultaneous to the measurement of the HRR values. This simultaneity in both types of measurements allows one to find correlations between different variables. These correlations would help to make predictions on unknown variables in the framework of fire models.

Keywords: calorimetry, heat release rate, forest fuels, short open path FTIR spectroscopy.
\end{abstract}




\section{Introduction}

The characterization of combustion properties and flammability of forest fuels is not a straightforward task. Forest fuel combustion is a complex process with multiple interrelated components, some of which have not yet been measured. There is a general agreement that the Heat Release Rate (HRR) of a fuel is one of the most important characteristics for understanding the combustion process, fire characteristics and fire propagation rate. Physical models take into account the complex phenomena to relate combustion variables (energy and gases emitted) with fire front behaviour. Nevertheless, validation of the prediction offered by models is complex because instrumental techniques are not available to measure HRR and gases directly. In addition, understanding the complex forest fire combustion necessarily involves the simulation of the phenomena at the benchscale approach. However, there is no universally accepted methodology for forest fuels, and many approaches have been evaluated for applying bench-scale devices to the study of these types of fuels.

The quantification of the frontal fire intensity of fires, expressed as heat-release rate per unit length is usually estimated from the mass loss rate through the Byram equation:

$$
I=H \cdot w \cdot r
$$

where $I$ is the frontal fire line intensity $(\mathrm{kW} / \mathrm{m}), H$ is the heat of combustion $(\mathrm{kJ} / \mathrm{kg}), w$ is the fuel consumption on an area basis $\left(\mathrm{kg} / \mathrm{m}^{2}\right)$ and $r$ is the fire spread rate $(\mathrm{m} / \mathrm{s})$. There is a controversy about the correct value of $H$ used for forest fuels. Several authors propose the use of the net heat of combustion obtained in an oxygen bomb, using $18 \mathrm{MJ} / \mathrm{kg}$ as a medium value for forest fuels. Nevertheless other authors proposed a value of $15 \mathrm{MJ} / \mathrm{kg}$, incorporating a nominal $15 \%$ radiation loss and an additional heat loss due to evaporation of all fuel moisture. This value is the upper limit obtained for flaming combustion of conifers in large scale experiments $(12-15 \mathrm{MJ} / \mathrm{kg})$, showing the importance of determining the heat of combustion during the flaming phase, which is much lower than in the glowing phase and strongly dependent on moisture content. Forest modellers traditionally do not pay attention to this variable because it is considered that it introduces little error into the energy calculation compared with $r$ and $w$, and because it has been considered as a constant. Calorimetry studies show the significant differences of HRR and $H$ among species, so the influence of these variables during the forest fire behaviour must be clarified. On the other hand, bulk density has important implications in flammability because forest fuels are irregular porous fuels and the natural diffusion of air affects the combustion process. To sum up, the complexity of the heat release estimation in forest fires is limited by the correct measure of variables involved. The need to understand the complex forest fire combustion (rapid flaming combustion in porous fuel with a low bulk density along a dynamic fire front) necessarily involves the simulation of the phenomena at the bench-scale approach. 
In this work a specific study has been performed that is focused on studying the influence of the fuel moisture content and bulk density on the measurements performed by the MLC-FTIR.

\section{Experimental}

\subsection{Experimental devices}

\subsubsection{The Mass Loss Calorimeter (MLC)}

The Mass Loss Calorimeter (MLC) was manufactured by Fire Testing Technology Limited (FTT $\left.{ }^{\circledR}\right)$. This apparatus (fig.1) is the complete fire model of the cone calorimeter, which has assumed a dominant role in bench-scale fire testing of building materials. A chimney made of stainless steel $(600 \mathrm{~mm}$ long $\mathrm{x}$ $114 \mathrm{~mm}$ inner diameter) and containing a thermopile of four mineral insulated inconel sheathed thermocouples (type $\mathrm{K}, 1.6 \mathrm{~mm}$ diameter) was added to the MLC (650 $\mathrm{mm}$ above the holder surface). The thermopile output was first calibrated by use of a methane burner and a flow meter, and then used to quantify heat release [1].

The MLC standard sample holder contained low density ceramic wool to ensure correct positioning of the samples, $25 \mathrm{~mm}$ from the conical heater, and the sample was placed on aluminium foil. A specific holder adapted for forest fuels samples was also designed to simulate rapid flaming combustion [2]. The holder $\left(10 \times 10 \times 5 \mathrm{~cm}^{3}\right)$ was made of stainless steel, with small uniformly sized holes over the entire outer surface (sides and bottom). These holes create an open space for inlet combustion gases to pass into the holder and through the fuel samples (Figure 1).

The MLC device and the porous holder have been evaluated and comply with the repeatability criteria established by different authors [3-5].
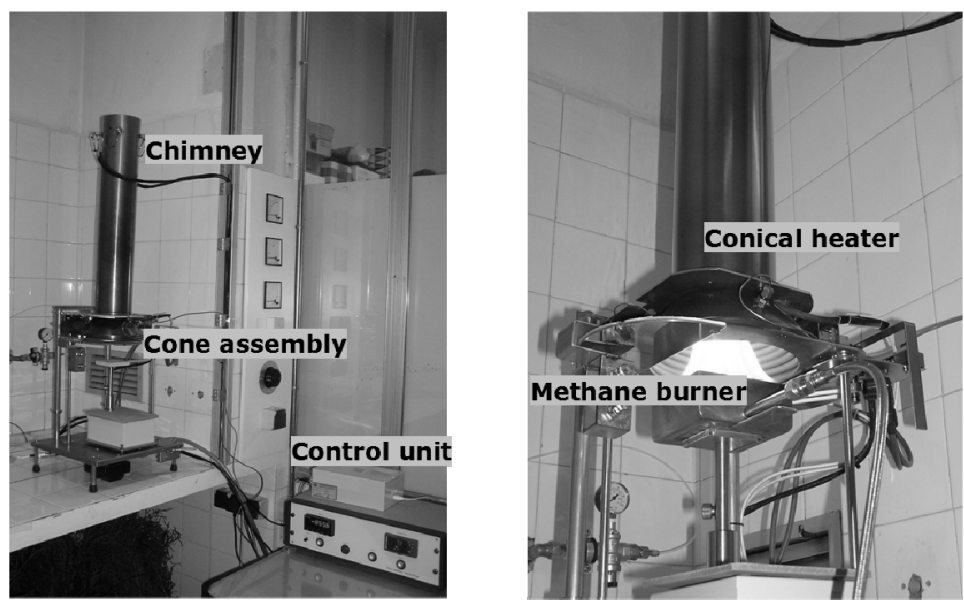

Figure 1: Experimental device at the INIA-CIFOR laboratory. (Left) General view. (Right) Methane burner calibrating the thermopile. 


\subsubsection{The open-path FTIR spectroradiometer}

Traditionally, extractive methods are the most common ones to analyze gas composition in a great variety of problems. However, they present some issues that must be considered carefully. The most important is the need to conduct the gas sample to the analyzer, a process that can involve modifications in the chemical composition of the analyzed gas.

Remote sensing techniques overcome some of these problems. One of the main advantages of remote sensing is that it is a non intrusive method that does not require the collection of samples, avoiding any alteration of the analyzed gas. In this sense, open-path FTIR Spectroscopy appears to be a very interesting technique that combines the advantages of the FTIR spectroscopy with the remote sensing principles. The open-path setup consists of a source of infrared energy and a FTIR spectroradiometer that measures the infrared energy coming to the instrument. The analysis of the absorption bands provides qualitative and quantitative information on the gases that are present at the path between the IR source and the spectroradiometer.

In this work an FTIR spectroradiometer working in an open-path configuration has been coupled to the MLC to analyze in-situ gas concentrations. In this sense, the MLC appears to be the most interesting configuration to do that. The heat unit in the MLC is exactly the same than in a standard cone calorimeter. Instead of the complex exhaust and gas sampling and analyzing system, the MLC has a "chimney-like" thermopile. The main function of the thermopile is to measure the heat release rate curves, but for our purposes also can serve as a duct to conduct the gaseous by-products of the combustion. Then the open-path system can be mounted in such a way that the optical line of sight of the spectroradiometer is only a few $\mathrm{cm}$ above the exhaust duct. In this way, radiation coming from the hot metallic wall of the thermopile is avoided, and only absorption from the gases at the exhaust will be measured. Fig. 2 shows the proposed configuration.

The main characteristics of the open-path system used for these experiments are:

a) The infrared source is an electric radiator powered at $400 \mathrm{~W}$. In this way, the surface reaches a temperature around $600^{\circ} \mathrm{C}$ working as a very nice IR radiator in the medium infrared (MIR) spectral range.

b) The spectral resolution selected has been $0.5 \mathrm{~cm}^{-1}$ (the best one that provides the MIDAC-AM model of spectroradiometer) in order to measure properly the fine structure of the $\mathrm{CO}$ absorption band and to take advantage of this resolution to retrieve in the best experimental conditions other gases. For this resolution, each spectrum takes 1.7 seconds to be acquired.

c) The number of scans selected is two. This is the most adequate value that minimizes the acquisition time preserving and adequate signal-to-noise ratio.

Figure 2 presents a scheme of the typical experimental set up. Distances between the infrared source and the spectroradiometer are around $320 \mathrm{~cm}$. It is important to note that this distance is not critical for the quantitative retrieval of concentrations, although it is very convenient to maintain it for the different experiments in order to assure a similar level of energy impinging at the detector. 

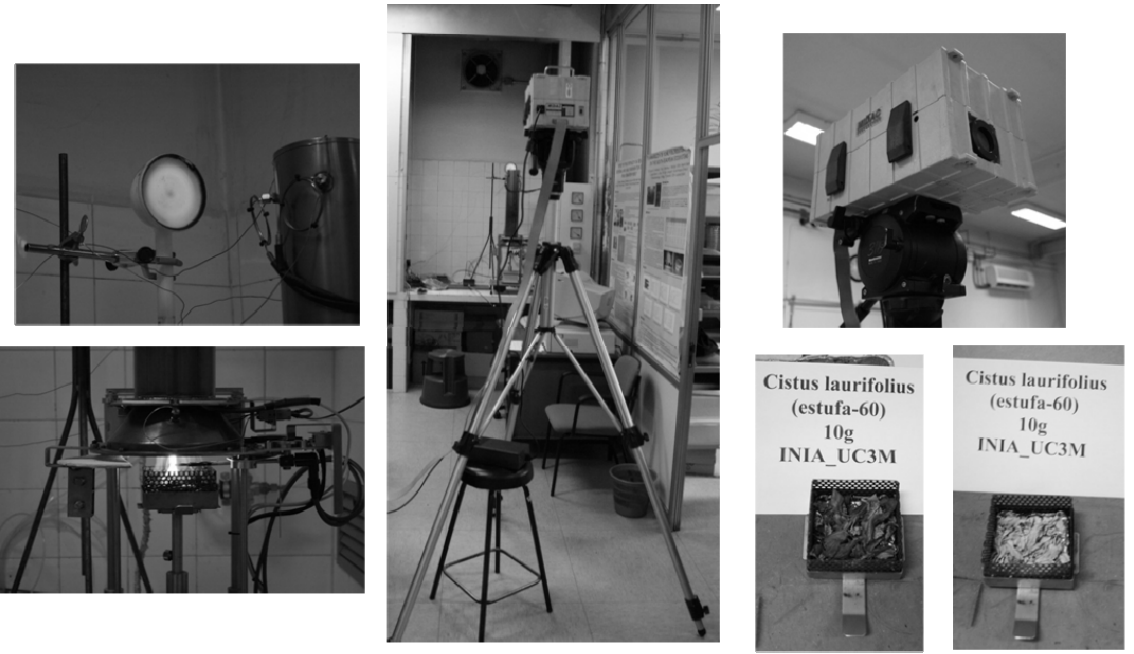

Figure 2: General view of the MLC-FTIR set up (centre) and different details of the experimental configuration.

\subsection{Sample preparation}

A series of tests, using Cistus ladanifer L. samples (leaves and twigs $<1 \mathrm{~cm}$ diameter) was carried out to determine the combustion characteristics of the forest fuel bed. The fuel moisture content (FMC) was controlled. The resulting FMC's, calculated on an oven-dry basis after drying the samples at $60^{\circ} \mathrm{C}$ to constant weight, were $\sim 110 \%, \sim 75 \%, \sim 40 \%$ and $0 \%$ (oven-dry). Three replicates were tested for each holder in order to comply with the repeatability criteria $(n=12)$. The initial sample dry mass selected was $10 \mathrm{~g}$ and the resulting thickness of the mass was $5 \mathrm{~cm}$. In accordance with the volume of the holder, the experimental conditions correspond to a bulk density of $\sim 20 \mathrm{~kg} / \mathrm{m}^{3}$ (representative of a bulk density value under field conditions). A constant heat flux of $50 \mathrm{~kW} / \mathrm{m}^{2}$ was selected in the electric conical heater for exposure of the samples because a similar value was expected in the wind tunnel tests. The MLC adapted design porous holder was used. The sample uniformly covered its exposed surface area. The spark igniter was used to provide the piloted ignition [6].

\section{Results and discussion}

\subsection{Repeatability of the measurements}

Fig. 3 illustrates the level of repeatability expected for these experiments. Three replicates have been tested for each experimental condition. 


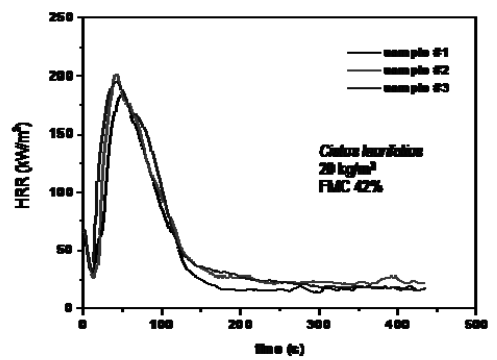

(a)

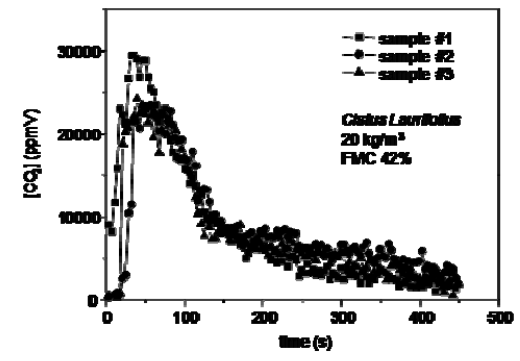

(b)

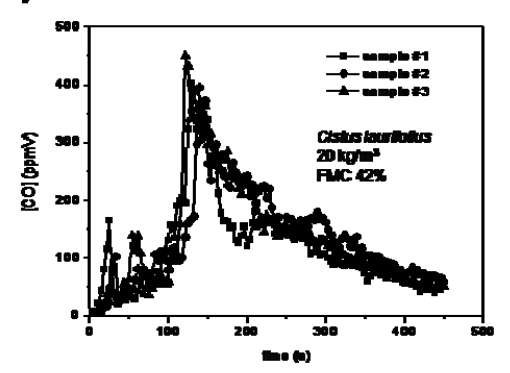

(c)

Figure 3: Experimental curves of $\mathrm{HRR}$ (a), $\mathrm{CO}_{2}$ (b) and $\mathrm{CO}$ (c) volume mixing ratios measured for a series of three replicates with $C$. laurifolius and a fuel moisture content of $42 \%$.

As can be seen, an acceptable repeatability is obtained. Taking into account the difficulty to work with biomass as a sample, this repeatability is indicative of an appropriate sample preparation procedure.

\subsection{Data analysis}

Fig. 4 is an example of the correlations between the thermodynamic variables and the emission of gaseous products as a function of time. Two different regimes (flaming and non-flaming) for the combustion can be clearly determined by studying the temporal evolution o these variables. Most of the heat is released during the flaming combustion, which is characterized by a good oxidation of the carbon fuel to a $\mathrm{CO}_{2}$ gaseous phase. During the smouldering combustion the released heat tends to be negligible, whereas a poorer combustion with predominant oxidation of the carbon to a $\mathrm{CO}$ gaseous phase is clearly detected. As can be seen, the temporal evolution of the $\mathrm{CO}$ concentration is a very good indicator of the state of the combustion process, and it is easy to identify and separate from this evolution the flaming and the smouldering phases. HRR curves are clearly related to the flaming combustion, when most of the $\mathrm{CO}_{2}$ is released. 
The results are shown as curves of HRR plotted against time (1 second frequency) and the following numerical results from the series of tests: Time to Ignition (TTI, s), Flame Duration (FD, s), FD before time to peak HRR (bFD, s), Peak HRR (PHRR, $\mathrm{kW} / \mathrm{m}^{2}$ ), average of HRR during flaming combustion (HRR, $\mathrm{kW} / \mathrm{m}^{2}$ ), Total Heat Release during flaming combustion (THR, MJ), THR before time to peak HRR (bTHR, MJ), Average Effective Heat of Combustion during flaming phase (AEHC, MJ/kg), Peak Effective Heat of Combustion (pEHC, $\mathrm{MJ} / \mathrm{kg}$ ), Average Effective Heat of Combustion before time to peak EHC (bEHC, MJ/kg), Average Mass Loss Rate during flaming phase (MLR, g/s), peak Mass Loss Rate (pMLR, g/s), MLR before time to peak MLR (bMLR, g/s), Residual Mass Fraction (RMF, \%) and Residual Mass Fraction before time to peak HRR (bRMF, \%).

An exploratory analysis was developed using non-parametric tests (Spearman $\mathrm{R}$ tests) in order to relate peak $\mathrm{CO}_{2}$ concentration with combustion parameters during flaming phase. FMC was also considered as independent variable in order to detect the influence in maximum $\mathrm{CO}_{2}$ concentration. The Partial Least Square (PLS) regression model (SIMPLS algorithm) was used to explore the relationship between peak $\mathrm{CO}_{2}$ (considered as dependent variable) and the most significant combustion parameters previously detected (considered as predictive variables). Statistica 6.0 package $^{\circledR}$ was used to analyze these data.

Fig. 5 shows HRR and $\left[\mathrm{CO}_{2}\right]$ curves for different moisture contents tested. The typical progression of a test is shown: ignition is produced, the heat release rate rises quickly and the peak (PHRR) is reached, then the HRR decreases until

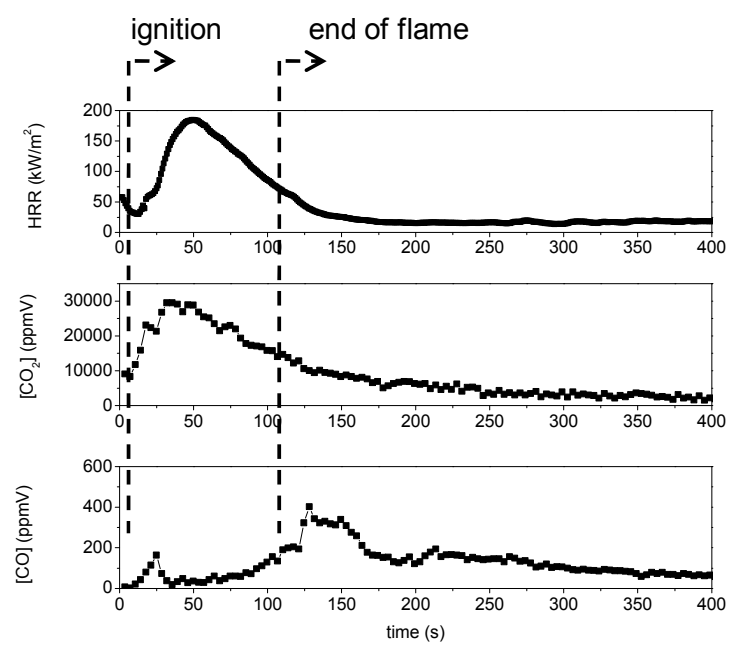

Figure 4: A comparison of the temporal evolution of different magnitudes measured for C. laurifolius with a fuel moisture content of $42 \%$. The beginning and end of the piloted flaming combustion is indicated by the dashed lines. 
22 Modelling, Monitoring and Management of Forest Fires II
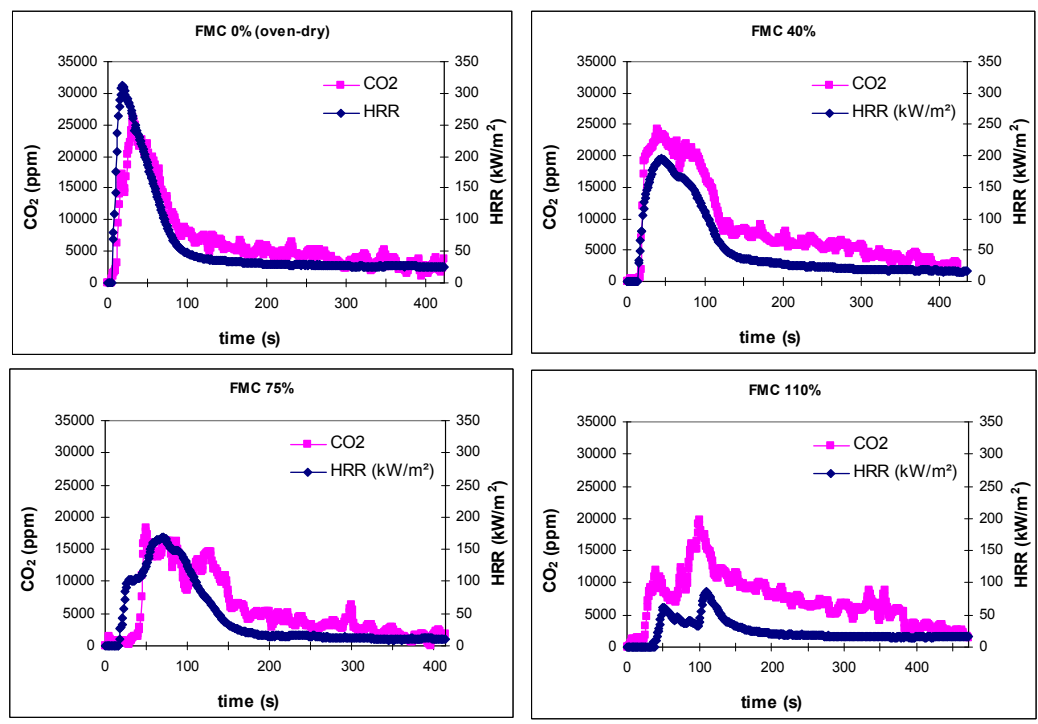

Figure 5: $\quad \mathrm{HRR}$ and $\left[\mathrm{CO}_{2}\right]$ curves for each FMC tested.

Table 1: Paired-correlations between $\left[\mathrm{CO}_{2}\right]$ and independent variables analysed.

\begin{tabular}{|c|c|c|}
\hline & Spearman $\mathbf{R}$ & p-level \\
\hline $\mathrm{CO}_{2} \& \mathrm{FMC}$ & $-0,693530$ & 0,017943 \\
\hline $\mathrm{CO}_{2} \& \mathrm{TTI}$ & $-0,633259$ & 0,036475 \\
\hline $\mathrm{CO}_{2} \& \mathrm{FD}$ & $-0,246014$ & 0,465874 \\
\hline $\mathrm{CO}_{2} \& \mathrm{bFD}$ & $-0,493156$ & 0,123222 \\
\hline $\mathrm{CO}_{2} \& \mathrm{HRR}$ & 0,672727 & 0,023313 \\
\hline $\mathrm{CO}_{2} \& \mathrm{pHRR}$ & 0,609091 & 0,046696 \\
\hline $\mathrm{CO}_{2} \& \mathrm{bEHC}$ & 0,863636 & 0,000612 \\
\hline $\mathrm{CO}_{2} \& \mathrm{pEHC}$ & 0,490909 & 0,125204 \\
\hline $\mathrm{CO}_{2} \& \mathrm{AEHC}$ & 0,618182 & 0,042646 \\
\hline $\mathrm{CO}_{2} \& \mathrm{bMLR}$ & 0,454545 & 0,160145 \\
\hline $\mathrm{CO}_{2} \& \mathrm{pMLR}$ & 0,451026 & 0,163816 \\
\hline $\mathrm{CO}_{2} \& \mathrm{MLR}$ & 0,045455 & 0,894427 \\
\hline $\mathrm{CO}_{2} \quad \&$ bTHR & $-0,009091$ & 0,978837 \\
\hline $\mathrm{CO}_{2} \& \mathrm{THR}$ & 0,645455 & 0,031963 \\
\hline $\mathrm{CO}_{2} \quad \& \mathrm{bRMF}$ & $-0,290909$ & 0,385457 \\
\hline $\mathrm{CO}_{2} \& \mathrm{RMF}$ & 0,463636 & 0,150901 \\
\hline
\end{tabular}



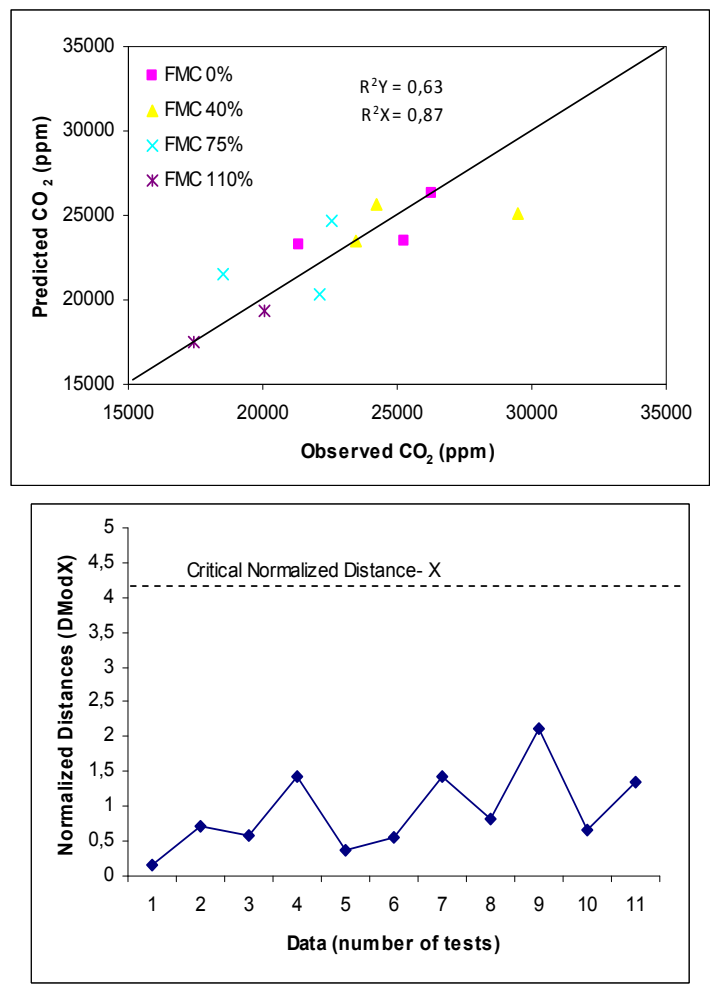

Figure 6: Goodness of fit and residual analysis for the partial least squares (PLS) model developed.

the end of flame and finally the glowing phase starts and continues until the end of the test. Curves also describe that FMC reduce time-to-ignition and HRR [2526] for the same bulk density $\left(20 \mathrm{~kg} / \mathrm{m}^{2}\right)$

Paired-correlations between peak of $\mathrm{CO}_{2}$ concentration (ppm) and selected combustion characteristics have shown in table 1. There was not flaming phase for one of the test for FMC $110 \%$ so this test was removed from the correlation analysis $(n=11)$. Results show a significant and positive correlation between peak $\mathrm{CO}_{2}$ concentration and typical combustion characteristics (MLC output) such us TTI, HRR, pHRR, AEHC and THR. Results also show the positive significant influence of time-heat flux history before the peak HRR (bEHC, $\mathrm{kJ} / \mathrm{kg}$ ) in peak $\mathrm{CO}_{2}$. The negative significant correlation between $\mathrm{FMC}$ and $\left[\mathrm{CO}_{2}\right]$ ratify the observed effect of FMC in combustion process detected in HRR curves.

PLS model was developed to relate $\mathrm{CO}_{2}$ concentrations with combustion characteristics using as predictors the significant variables previously detected. The results show that predictors (FMC, TTI, HRR, pHRR, AEHC, THR and bEHC) explain $63 \%$ of the variability of $\mathrm{CO}_{2}$ concentration $\left(\mathrm{R}^{2} \mathrm{Y}=0.63\right.$, Second 
Component, $\mathrm{n}=11)$. PLS model predicts reasonable well observed values and anomalous residuals were not detected (fig. 6).

\section{Conclusions}

An FTIR spectroradiometer has been coupled in a short open path configuration to measure in situ concentrations of $\mathrm{CO}, \mathrm{CO}_{2}$ and $\mathrm{H}_{2} \mathrm{O}$ obtained as combustion product of forest fuels during test performed in a Mass Loss Calorimeter. The ignition and flame time can be measured using the temporal evolution between the concentrations of $\mathrm{CO}$ and $\mathrm{CO}_{2}$ with the HRR. Correlations between these concentrations and typical magnitudes measured in a calorimetric test have been studied for different values of fuel moisture content in order to obtain prediction capabilities. Results show a significant and positive correlation between peak $\mathrm{CO}_{2}$ concentration and typical combustion characteristics (MLC output) such us TTI, HRR, pHRR, AEHC and THR and the influence of time - heat flux history before the peak HRR in peak $\mathrm{CO}_{2}$ concentration.

\section{Acknowledgement}

The authors want to acknowledge financial support from the Integrated Project FIRE PARADOX, FP-018505.

\section{References}

[1] International Organization for Standardization (2001). Simple heat release test using a conical radiant heater and a thermopile detector (ISO 13927), International Organization of Standardization, Geneva.

[2] Schemel, C.F., Simeoni, A., Biteau, H., Rivera, J.D. \& Torero, J.L. A calorimetric study of wildland fuels, Experimental Thermal and Fluid Science 32 (7): pp. 1381-1389, 2008

[3] Babrauskas, V. The cone calorimeter, in: SFPE handbook of fire protection engineering, $3^{\text {rd }} \mathrm{ed}$, National Fire Protection Association, Quincy MA, pp. 3-63-3-81, 2002.

[4] European Commission (1997). SBI round robins results Available from http://europa.eu.int/comm/enterprise/construction/internal/essreq/fire/sbirou nd/sbirep.htm .

[5] Janssens, M.L. Heat Release Rate (HRR), ,in: Measurement Needs for Fire Safety, Proceedings of an International Work-shop (NISTIR 6527), T.J. Ohlemiller, E.L. Johnson and R.G. Gann (Ed.), National Institute of Standard and Technology, Gaithersburg. pp. 186-200, 2001

[6] Madrigal, J, Hernando, C., Guijarro, M., Diez, C., Marine, E. \& de Castro, A.J. Journal of Fire Sciences 27, pp. 323-342, 2009 